\title{
ARTIGO DE REVISÃO \\ MIGDOLUS FRYANUS (WESTWOOD, 1863) (COLEOPTERA: VESPERIDAE): PRAGA DA CULTURA DE CANA-DE-AÇÚCAR
}

\begin{abstract}
L.A. Machado ${ }^{1}$; M. Habib ${ }^{2}$
${ }^{1}$ Instituto Biológico, Centro Experimental Central, CP 70, CEP 13001-970, Campinas, SP, Brasil. E-mail: laertemachado@biologico.sp.gov.br
\end{abstract}

RESUMO

Migdolus fryanus (Westwood, 1863) (Coleoptera: Vesperidae) é um besouro que ataca as raízes e o rizoma da cana-de-açúcar, ocasionando sérios prejuízos aos canaviais, principalmente, no Estado de São Paulo. As larvas são difíceis de serem controladas em função do comportamento subterrâneo e da profundidade que podem atingir em determinadas épocas do ano. É um inseto de ciclo longo e que apresenta revoada dos adultos para o acasalamento, após as chuvas do mês de outubro. Atualmente, para o controle desse inseto, alguns produtores de cana realizam um monitoramento por meio de armadilhas contendo feromônio sexual para localizar as áreas infestadas e, posteriormente, aplicar inseticidas no sulco, na época do plantio (cana planta), ou nos lados da linha após a colheita da cana (cana soca). Esta revisão enfoca estudos sobre os aspectos biológicos e comportamentais de $M$. fryanus.

PALAVRAS-CHAVE: Cana-de-açúcar, Migdolus fryanus, biologia, comportamento, controle.

\section{ABSTRACT}

MIGDOLUS FRYANUS (WESTWOOD, 1863) (COLEOPTERA: VESPERIDAE): PEST OF SUGARCANE. Migdolus fryanus (Westwood, 1863) (Coleoptera: Vesperidae) is a beetle that attacks the roots and rhizomes of sugarcane, causing serious damage in the state of São Paulo, Brazil. The insect has a long lifecycle, and the larva is usually protected due to its underground behavior as well as the depth it can reach in the soil at some times of the year. The adults engage in mating flights after the rains of October. Currently, for the control of this insect, the sugarcane growers use sex pheromone traps to find the infested areas, followed by the application of insecticides in the planting furrow at the moment of planting or at the sides of the rows after the harvesting of the sugarcane. This review of the literature concerns biological and behavioral aspects of $M$. fryanus.

KEY WORDS: sugarcane, Migdolus fryanus, biology, behavior, control.

\section{Sistemática do gênero Migdolus}

A subfamília Anoplodermatinae de Gú́RINMéNevilLe (1840), na qual está o gênero Migdolus, foi considerada como uma subfamília de Cerambycidae por Duffy (1953) e Crowson (1955).SvÁcha et al.(1997) transferiram esta subfamília para afamília Vesperidae. A seguir é apresentada uma classificação do gênero Migdolus, que compreende 10 espécies, conforme revisão de DiAs (1984), incluindo a sinonímia do gênero Migdolus e da espécie $M$. fryanus

Ordem: Coleoptera

Subordem: Polyphaga

Superfamília: Chrysomeloidea

Família: Vesperidae (SVÁcha et al.,1997)
Subfamília: Anoplodermatinae (GUÉRIN-MÉNEVILLE, 1840)

Tribo: $\quad$ Anoplodermatini (Guérin-MÉNEVILLE, 1840)

Gênero: $\quad$ Migdolus (WeSTWOOD, 1863) Paulistanus Gounelle, 1899 (Sinonímia)

Especies: $\quad$ brachypterus Lane, 1972 clypeatus Dias, 1984 cuyabanus Lane, 1937 exul (Lameere, 1915) fryanus Westwood, 1863 bouvieri GouneLLe, 1899 (Sinonímia) fonsecai Lane, 1972 (Sinonímia) goyanus Dias 1984

\footnotetext{
${ }^{2}$ Universidade Estadual de Campinas, Campinas, SP, Brasil.
} 
morretesi Fonseca, 1958 (não Lane, 1937)

punctatus Lane, 1937

spitzi Lane, 1937

hulanus (Lameere, 1902)

\section{Distribuição geográfica}

Com relação à distribuição geográfica as espécies desse gênero são geralmente raras, dada exceção a $M$. fryanus, que atualmente é uma das principais pragas da cultura da cana-de-açúcar no Estado deSão Paulo, sendo também constatada nos Estados do Paraná e Santa Catarina, na Argentina (Província de Corrientes) e no Paraguai (NunES, 1996).

TERÁn etal. (1983), TERÁNet al. (1984) e KASTENJUNIOR et al. (1985) relataram que $M$. fryanus era mais freqüente em regiões de solo arenoso. Na Tabela 1 é apresentada a relação das 10 espécies do gêneroMigdolus com suas distribuições, segundo Dias (1984).

Tabela 1 - Distribuição geográfica das espécies deMigdolus.

\begin{tabular}{lll}
\hline Espécie & Estado & País \\
\hline M. punctatus & SP & Brasil \\
M. fryanus & SP, PR, SC & Brasil,Paraguaie \\
& & Argentina \\
M. brachypterus & PR & Brasil \\
M. morretesi & SP & Brasil \\
M. cuyabanus & MT & Brasil \\
M. goyanus & GO & Brasil \\
M. spitzi & MS & Brasil \\
M. clipeatus & MT & Brasil \\
M. exul & RO & Brasil \\
M. thulanus* & Rota Goiás-Cuiabá & Brasil \\
\hline
\end{tabular}

*Sem indicação precisa de localidade.

\section{Importância econômica}

Espécies do gênero Migdolus têm ocasionado prejuízos severos em diferentes regiões do Estado de São Paulo e pode atacar diversas plantas, cultivadas ou nativas, sendo $M$. fryanus, a espécie dominante nas culturas de cana-de-açúcar do Estado de São Paulo (DiAs, 1984). De acordo com LANE (1937) a primeira constatação desteinseto como praga da cultura da canade-açúcarfoiem1927,noMunicípiodeIbaté,SP.Dentre ocomplexodepragas desoloqueocorremnoscanaviais, é a que apresenta menor número de informações sobre os aspectos biológicos e até mesmo não tendo o conhecimento se é a única espécie do gênero que se relaciona coma cultura. (NAKANO\&JOKO, 1969; ROCCIA, 1977;TERÁN et al., 1983; TERÁN et al., 1984; BENTO et al., 1992).
FONSECA (1958) ao relatar a M. morretesi como uma broca eventual da cultura da cana-de-açúcar e do eucalipto, citou a ocorrência de Migdolus causando prejuízos também ao cultivo de videira e amoreira. Para a amoreira o prejuízo foi de 5.000 estacas, no ano de 1953. Nesse mesmo relato o autor informa que no ano de 1943, a Cia. Refinadora Paulista, registrou em alguns talhões de plantações de eucaliptos, no Município de Tamoio, SP, um ataque de larvas que destruíram 20.000 plantas de dois anos de idade.

PigatTi et al. (1962) constataram ataques do inseto à cultura do algodoeiro e GRAVENA \& Busoli (1985) registraram a ocorrência em cultura de feijão irrigado, no Município de Jaboticabal, SP. Bento et al. (1995) citaram as culturas de café, mandioca e pastagens como hospedeiras desta praga.

WiLCKENet al.(2005) fizeram o primeiro registro de M. fryanus em mudas de plantios dePinus caribaea var. hondurensis (Sénée) Barr. \& Golf. no Estado de São Paulo, completando a relação de culturas econômicas que este besouro pode atacar. Segundo esses autores, no ano de 2000, em uma área de 33,46 ha da cultura, 10 ha foram atacadas pelo inseto, sendo registrado perdas acima de $25 \%$ das mudas plantadas.

As plantas nativas, cipó vermelho Dolicarpus rolandri, (Dileniaceae), cipó de São João Pyrostegia venusta (Bignoniaceae) e os cipós brancos, Bignonia sp. eAdenocalymmapaulistarum (Bignoniaceae), foram citadas por FonSECA (1958) comohospedeiras da espécie M. morretesi.

Os danos são provocados pelas larvas do inseto que são subterrâneas e destroem o sistema radicular das plantas. Dentre as culturas citadas, existem registros numéricos com relação a prejuízos e áreas infestadas, apenas para a cultura canavieira.

De acordo com levantamentos efetuados em 1992, pela Cooperativa Central dos Produtores de Açúcare ÁlcooldoEstado deSão Paulo-Copersucar, existia no Estado, naquela época, uma área atingida pelo inseto, de aproximadamente, 50.000 ha, com prejuízos da ordem de U\$ 45 milhões de dólares, o que apontava uma queda de $25 \%$ da produção, nas áreas afetadas. Em 1995, incluindo todas as regiões produtoras do Estado, estimou-se que as áreas atingidas porMigdolus spp. ultrapassava a 100.000 ha de cana-de-açúcar (BENTOet al.,1995). Segundo esses mesmos autores, na Região do Pontal do Paranapanema, SP, ataques de Migdolus spp., na cultura da amoreira, tem quase que inviabilizado a criação do bicho-da-seda.

Devido as poucas informações sobre a biologia desse inseto, ainda não se estabeleceu o nível econômico de danos e nem ações eficientes para o seu controle. KASTEN JUNIOR. et al. (1988) relataram que em uma área onde se cultivava eucalipto e, posteriormente, foi plantada com cana-de-açúcar, na Usina Amália Município de Santa Rosa do Viterbo, SP, os 
ataques de Migdolus foram tão severos que houve necessidade de reforma do canavial após um e dois cortes da cultura.

As perdas provocadas por esse inseto podem variar de 25 a 30 toneladas de cana por hectare até, na maioria dos casos, a completa destruição da lavoura, resultando na reforma antecipada, mesmo decanaviais de primeiro corte (BENTo et al., 1995).

\section{Aspectos biológicos e comportamentais}

Os adultos de $M$. fryanus normalmente têm vida efêmera; vivem pouco tempo após a cópula e a postura, as quais podem ocorrer alguns dias depois da emergência. Em contraposição, a fase larval é longa, quase sempre de um ano, podendo prolongar-se a dois ou três (Bentoet al., 1995, NAKANo et al., 2001). As larvas de $M$. fryanus têm hábito subterrâneo, podendo atingir até 4 a $5 \mathrm{~m}$ de profundidade (ARRIGONI, 1988). Esse comportamento tem dificultado estudos biológicos do inseto .

GOUNELLE (1899) e BRUCH (1921) foram os primeiros a registrar alguns dados sobre as atividades biológicas dos adultos de duas espécies de Anoplodermatini. O primeiro autor fez referência a $M$. fryanus, no Vale do Rio Pardo, SP, no ano de 1898, informando que a fêmea tem vida subterrânea e que ambos os sexos foram encontrados ao longo de pequenos caminhos, depois das chuvas. Ainda, esse autor relata que o macho era bastante ativo, voava bem, ao passo que a fêmea era áptera e vagarosa. Já o segundo autor, citou observações realizadas em 1918, por Diurione, curador do Museu de La Plata, o qual informava que a fêmea de M. orbignyi Blanchard, fora encontrada no solo a pouca profundidade e que 3 machos procuravam penetrar na terra. Dias mais tarde, pelo período da manhã, teve a oportunidade de coletar mais um casal da espécie. Desta vez, a fêmea se encontrava com a metade do corpo para fora do solo e o macho ao redor dela, muito agitado.

Em seu desenvolvimento biológico $M$. fryanus, como inseto holometabólico, apresenta quatro estágios: ovo, larva, pupa e adulto. Os ovos têm formato cilíndrico e cor branco leitosa, medindo aproximadamente 4,5 mm de comprimento, sendo extremamente frágeis sendo depositados individualizados no solo, em profundidade variável de 1,6 a $4 \mathrm{~m}$, provavelmente, entre os meses de janeiro a março (ARRIGONI, 1988).

FONSECA (1958) descreveu larvas de M. morretesi como de formato cerambiciforme, de coloração branco leitosa, com pernas atrofiadas e a região anterior do corpo mais avantajada. Nos segmentos abdominais ocorrem expansões dorsais em forma de calombos mais ou menos oblongas, transversais e as da região ventro-lateral voltadas para a parte posterior do corpo, em arco, com o formato de meia lua. Segundo o autor essas projeções dos segmentos abdominais funcionam como pseudópodos para auxiliar no deslocamento da larva pelo interior das galerias no solo. $\mathrm{Na}$ fase final do desenvolvimento a larva pode atingir aproximadamente $50 \mathrm{~mm}$ de comprimento.

ARrigoni (1988) ao estudar a flutuação populacional da praga, observou grande variação na população de larvas, nas diferentes camadas do solo (0 a $5 \mathrm{~m}$ de profundidade) em função das épocas de amostragem. A maioria, 55,6\% da população foi encontrada no primeiro metro de profundidade.

A metamorfose se procede no solo onde a larva constrói uma câmara pupal. A pupa apresenta coloração branco amarelada e deve viver neste estágio por um curto período de tempo. SANSIGOlo et al. (1981) encontraram 2 exemplares de pupa de $M$. fryanus em profundidade de 2,7 e 3,2 m, no Município de São Manoel, SP, concordando com ARRIGONI (1988) que encontrou a maioria das pupas $(61,9 \%)$, à profundidade de 3 a $4 \mathrm{~m}$.

Após a metamorfose a fase adulta permanece em dormência por longo período, fator observado por ARRIGONI (1988) que coletou adulto no campo, e em condições de laboratório (temp. $25 \pm 2^{\circ} \mathrm{C}$ ), manteve por até 4 meses. Segundo esse mesmo autor os adultos dormentes apresentam a região abdominal expandida, ultrapassando o ápice dos élitros.

Os besouros adultos apresentam acentuado dimorfismo sexual. Os machos possuem antenas maiores, coloração preta (maioria), asas posteriores funcionais para vôo, o que os tornam mais abundantes no ambiente externo. As fêmeas a presentam tamanho menor, antenas menores, coloraçãocastanho-avermelhada ou castanho-escura. As asas posteriores são rudimentares e muito estreitas, sendo impróprias para vôo,desta forma, são menos freqüentes no ambiente externo (DiAs, 1984).

Os adultos não se alimentam e os machos, após o começo das revoadas vivem em média de 4 a 7 dias. Já as fêmeas podem viver de 7 a 38 dias e após a cópula depositam de 14 a 45 ovos, os quais têm um período de incubação variável de 17 a 23 dias (ARRIGONI, 1987).

Na fase adulta são escavadores e estão presentes na superfície do solo a partir do mês de outubro, assim que se iniciam as primeiras chuvas. $\mathrm{O}$ aparecimento dos machos écontrolado pelas fêmeas que liberam um feromônio sexual de atração, provocando um fenômeno denominado de "revoadas deMigdolus", que ocorrem após as chuvas, variando de uma região para outra e podendo acontecer até no mês de março (BENTO et al., 1992).

Em um estudo de campo, Pizano (1991) observou que o horário das revoadas ocorreu entre 9 h e 13h. Já para BENTO et al. (1993) as fêmeas normalmente apareceram no período da manhã, no horário compreendido entre $8 \mathrm{~h}$ às $12 \mathrm{~h}$, podendo ser percebidas pelos 
machos, ainda dentro do solo. MACHADO (2006) estudando revoadas de Migdolus em 4 Municípios de São Paulo relatou que as fêmeas apareceram na superfície do solo em horário bem definido, sempre entre $8 \mathrm{~h}$ e 10h da manhã e que diversos machos foram atraídos por uma única fêmea, quando ela deixava a galeria expondo-se a eles, para a realização da cópula.

\section{Controle}

Pigatti et al. (1962) relatam que a redução populacional da praga através de arações dos talhões atacados, seguidos da destruição das soqueiras pelo fogo, não promoveu êxito no controle. Por ocasião da implantação de nova cultura de cana-de-açúcar, no mesmo local, verificou-se novamente o ataque da praga causando prejuízos totais. Esses mesmos autores avaliaram, em condições de laboratório, 14 inseticidas, incluindo-se clorados (7), fosforados (4) clorofosforado (2) e um carbamato, que foram aplicados em forma de polvilhamento, a vácuo parcial, diretamente sobre as larvas. Pelos resultados, constataram que apenas o inseticida EPN causou mortalidade total das larvas, após 48 horas da aplicação.

Com relação a ensaios de campo, estudos preliminares realizados por Pigatti et al. (1966) utilizando vários inseticidas, demonstraram que o Endosulfan $4 \%$ (350 g para 25 m de sulco) e o Azinphos-metil 1,5\% (700 g para $25 \mathrm{~m}$ de sulco) promoveram uma proteção à cana-de-açúcar por um período de 8 meses. Complementarmente, Pigatti \& Pigatti (1968) evidenciaram que canaviais tratados com Endosulfan mantiveramse isentos de ataques de Migdolus até 17 meses após o plantio.

Roccia (1977) utilizando vários inseticidas não obteve resultados satisfatórios de controle, uma vez queem todas parcelas tratadas constatavam-se sinais visíveis de ataques e a presença de larvas. Entretanto, NOVARETTI et al. (1983) estudando os inseticidas Furadan5G, $80 \mathrm{~kg} / \mathrm{ha}$; Marshal5G, $80 \mathrm{~kg} / \mathrm{ha}$; Aldrin $5 \mathrm{PS}, 15 \mathrm{~kg} / \mathrm{ha}$; Thiodan, $35 \mathrm{CE}, 11,5 \mathrm{~L} /$ ha eHeptacloro $40 \mathrm{CE}, 1,87 \mathrm{~L} /$ ha obtiveram melhores resultados de controle com o inseticida Thiodan, seguido do Heptacloro, os quais proporcionaram aumento de produção da ordem de 19 e 17 ton. de cana/ha, respectivamente, em relação à testemunha.

Segundo TERÁn et al. (1988) os inseticidas Endosulfan e Heptacloro, quando utilizados associados á matéria orgânica, reduziram os prejuízos causados por Migdolus a cultura de cana-de-açúcar. KASTEN JUNIOR. et al. (1989) compararam o inseticida Heptacloro 40 CE com os granulados Clorpirifós 10 CR e Paration 14 CR contra pragas de solo, por um período de 2 cortes. Pelos resultados, nota-se que, para Migdolus apenas o inseticida Heptacloro destacou-se promovendo o controle da praga.
Dada a importância econômica de $M$. fryanus para a cultura da cana-de-açúcar, diversos inseticidas para o uso em solo têm sido testados, mas poucos têm sido utilizados comercialmente. Observa-se que as maiorias dos produtos aqui relatados, atualmente, são de uso proibido devido os efeitos cumulativos no homem e no meio ambiente.

No que diz respeito a agentes de controle biológico, Pizano et al. (1985) relataram a ocorrência do nematóide entomopatogênico Steinernema glaseri (Steiner, 1929) (Rhabditida: Steinernematidae) parasitando ovos e larvas de $M$. fryanus em cultura de cana-de-açúcar, no Estado de São Paulo.

ARrigoni et al. (1986a) estudaram 4 raças exóticas do nematóide entomopatogênico Steinernema (= Neoplectana) carpocapsea. Os resultados mostraram que as 4 raças avaliadas não reduziram a população das larvas de Migdolus spp. No entanto, os autores constataram a presença de populações nativas de nematóides do gênero Rhabditis que, segundo os autores, atuaram de maneira mais significativa no controle do inseto.

PizANo et al. (1987) realizaram levantamentos em áreas infestadas por Migdolus com objetivo de avaliar onível de parasitismo denematóide sobre a fase larval do inseto, em duas épocas distintas do ano (maio e agosto) e constataram um índice de parasitismo de $3,26 \%$ no mês de maio e $7 \%$ no mês de agosto.

Em uma pesquisa de laboratório, MACHADO et al. (2005) estudaram a patogenicidade dos nematóides entomopatogênicos, nativos, Heterorhabditis indica Poinar, Karunakar \& David, 1992 (Rhabditida: Heterorhabditidae) (IBCB-n5) e S. glaseri contra ovos, e larvas, de $M$. fryanus e concluíram que os nematóides têm potencial para serem pesquisados como agentes de controle biológico do inseto em cultivo de cana-deaçúcar.

A identificação e a síntese do feromônio sexual da fêmea de M. fryanus foium grande avançonos estudos com essa praga. PIZANo (1991) ao estudar o potencial de controle de $M$. fryanus através de armadilhas de feromônios sexual, capturou um número médio de 30 insetos por armadilha e observou que o horário das revoadas ocorreu entre as $9 \mathrm{~h}$ e $13 \mathrm{~h}$, com maior freqüência às 13h. De acordo com Leal et al. (1994) o principal componente químico do feromônio sexual de $M$. fryanus é uma amida, o N-(2'S)-methylbutanoyl 2 methylbutylamine. Segundo esse autor, $1,0 \mathrm{mg}$ deste feromônio, quando usado em condições de campo, é capaz de capturar 2,7 vezes mais macho que duas fêmeas virgens juntas. A formulação é em peletes ou pastilhas que são insolúveis em água, além de resistir à radiação solar, podem permanecer por vários dias em condições de campo sob chuva.

Por outro lado, a possibilidade do produtor realizar coleta massal por intermédio dessas armadilhas 
é dificultado devido o seu alto custo de mercado, por se tratar de um produto fabricado fora do Brasil.

Pela biologia e pelo comportamento nota-se que $M$. fryanus é um inseto de difícil controle, além disso, é quase impossível uma previsibilidade exata dos talhões onde o inseto irá aparecer em cada ano. Com isso, faz-se necessário o emprego de medidas de controle basicamente por toda área de plantio da cultura da cana-de-açúcar, elevando o custo da produção.

De acordo com MACHADO et al. (2003), atualmente, os produtores de cana-de-açúcar, de uma maneira geral, adotam um sistema de manejo para $M$. fryanus que envolve três tipos de controle: cultural, químico e comportamental, e levam em consideração o fato de ser cana planta ou cana soca.

\section{Prática cultural}

Esse método traz o inconveniente ao produtor da necessidade de reforma antecipada do canavial e consiste inicialmente da destruição das plantas atacadas. Visa, além da morte de larvas pela ação do implemento, a sua exposição a organismos predadores e condições climáticas adversas. Para isso, há de se considerar dois pontos importantes: a época de execução do trabalho e os implementos a serem utilizados.

Estudos da flutuação populacional de larvas de $M$. fryanus têm mostrado que a época do ano que se encontra a maior número de larvas nos primeiros 20 a $40 \mathrm{~cm}$ do solo, coincide com os meses mais frios e secos do ano, (março a setembro) (MACHADO, 2006). Com relação ao implemento a ser utilizado, já existe no mercado um destruidor de soqueira, modelo Copersucar, que pode reduzir a população das larvas em mais de $80 \%$ quando comparado com grades aradoras (ARRIGONI et al., 1986 b).

De acordo com ARRIGONI et al. (1986b), a grade aradora em 3 passagens na mesma área, foi o implemento que mais reduziu a população de larvas de Migdolus, pela destruição das soqueiras, causando 94,5\% de mortalidade. Posteriormente a eliminação das soqueiras, já nas épocas das chuvas, (outubro a dezembro), com auxílio de um arado aiveca, realizase uma aração mais profunda $(40 \mathrm{~cm})$. Desta vez, associada com o controle químico, quando se aplica inseticida no fundo do sulco, através de bicos colocados atrás das bacias do arado de aiveca, para formar uma faixa protetora continua.

\section{Controle químico}

Atualmente, encontra-senomercado, com registro para o controle deM.fryanus, os inseticidasendosulfan, fipronil e imidaclopride, os quais devem ser aplicados da forma como descrita abaixo.
Em áreas de implantação da cultura e com baixas incidências da praga recomenda-se uma única aplicação com auxílio de pulverizadores tratorizados, adaptados com bico tipo leque, com vazão de $300 \mathrm{~L}$ decalda por hectare, no fundoe nas paredes do sulco de plantio, no momento da cobertura dos toletes de cana, com a dosagem recomendada pelo fabricante. Áreas com altas infestações, utilizar o parcelamento de doses, conforme recomendações dos fabricantes dos produtos, aplicando a primeira parcela na ocasião da renovação do canavial, quando se faz a prática cultural, complementando posteriormente, com a segunda parcela no momento da realização da cobertura da cana no sulco. Nas áreas de cana soca (pós-colheita), o produto escolhido deve ser aplicado com implemento especifico que incorpora a calda nos dois lados da linha da cana, a uma profundidade variável de 10 a $20 \mathrm{~cm}$. Para esse método recomenda-se uma pulverização com um consumo de água variável de 400 a 1.200 L por hectare (MACHADOet al., 2003).

\section{Controle por comportamento}

Esse método visa à captura de machos adultos através de armadilhas de feromônio sexual, na ocasião das revoadas. Desta forma, interfere-se no acasalamento do inseto e conseqüentemente, afeta sua nova geração. Embora haja boas perspectivas para a adoção desse sistema pelos usineiros, existem poucas pesquisas realizadas com o feromônio sexual.

BENTO et al. (1995) recomendaram o controle por comportamento realizando-se inicialmente um monitoramento através de levantamentos sistemáticos da população da praga por meio de armadilhas de feromônios sexual, distribuídas na plantação ao longo dos carreadores (1 a 10 armadilhas a cada 10 ha). Segundo os autores a cada 1 a 2 dias deve-se vistoriar as armadilhas, sendo aconselhável a troca dos peletes ou pastilhas a cada 15 a 20 dias. Detectado a presença de 2 machos adultos por armadilha, parte-se para coleta massal, que consiste em distribuir um número maior de armadilhas pelos talhões infestados (1 a 4 armadilhas/ha). Diversos tipos de recipientes têm sido adaptados como armadilhas, sendo hoje muito comuns garrafas plásticas tipo "Pet" utilizadas na embalagem de refrigerante e água mineral. Um dispositivo côncavo (tipo prato) é rosqueado na boca da garrafa contendo o peletes ou pastilha, sendo elas, enterradas rente ou ligeiramente abaixo da superfície do solo (Fig. 1). Diariamente, durante o período de revoadas, deve-se fazer a remoção dos besouros capturados. 

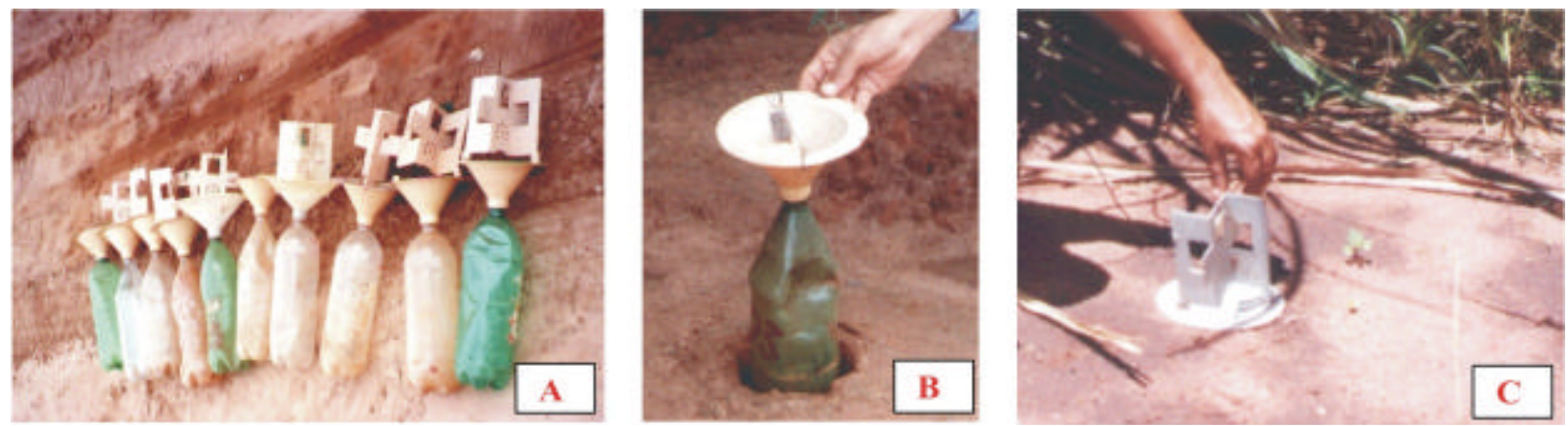

Fig. 1 -Seqüência (A, B e C) da instalação de armadilha de feromônio sexual para a captura de besouros machos deMigdolus fryanus em cultura de cana-de-açúcar.

\section{REFERÊNCIAS}

Arrigoni, E. B.; Dnardo, L.L.; Conde, A.J.; Teràn, F.O. Aplicação de Neoplectana carpocapsae Weiser, 1955 em condições de campo para o controle deMigdolus spp. (Coleoptera: Cerambycidae). Nematologia Brasileira, v.8, p.181-189, 1986a.

Arrigoni, E.B; Terán, F.O.; Kasten Junior, P.; Novaretti, W.R.T. Migdolus spp. broca dos rizomas da cana-deaçúcar. In: SEMINÂRIO DE TÉCNOLOGIA AGRONÔMICA CENTRO DE TECNOLOGIA COPERSUCAR, 3., 1986, Piracicaba, SP. Anais, Piracicaba, 1986b. p.129-142.

Arrigoni, E.B. Aspectos biológicos de Migdolus fryanus Westwood, 1863 (Coleoptera, Cerambycidae). In: CONGRESSO BRASILEIRO DE ENTOMOLOGIA, 7., 1987, Campinas, SP. Resumos. Campinas, 1987. p.107.

ArRigonı, E.B. Flutuação populacional deMigdolusfryanus Westwood, 1863 (Coleoptera: Cerambycidae). Boletim Técnico Copersucar, n.44, p.22-26, 1988.

Bento, J.M.S.; Albino F.E.; Della Lucia T.M.C.; Vilela, E.F. Field trapping of Migdolus fryanus Westood (Coleoptera: Cerambycidae) using natural sex pheromone. Journal Chemical Ecology, v.18, n.2, p.245251, 1992.

Bento, J.M.S.; Della Lucia, T.M.C.; Frighettor.T.S. Male response to natural sex pheromone ofMigdolusfryanus Westwood (Coleoptera: Cerambycidae) females as affected by daily climatic factors. Journal Chemical Ecology. v.19, n.10, p.2347-2351, 1993.

Bento, J.M.S.; Vilela, F. E.; Della Lucia, T.M.C.; Leal, W.S.; Novaretti, W.R.T. Migdolus: biologia, comportamento e controle. BENTO, J.M.S. (Ed.). Salvador, 1995. 58p.

BRUCH, C. Algunos interessantes Cerambicídos. RevistaDel Museo de La Plata, n.25, p.345-356, 1921.

Crowson, R.A. The natural classification of the families of Coleoptera. London: Nathaniel., 1955. vi + 187p.

DıAs, M.M. Revisão da subfamília Anoplodermatinae. Parte ITribo Anoplodermatini. GêneroMigdolusWestood, 1863. (Coleoptera, Cerambycidae). Revista Brasileira de Entomologia, v.28, n.4, p.507-535, 1984.

DuFF, E.A. A monograph of the immature stages of British and imported timber beetles (Cerambycidae). London: British Museum (NaturalHistory), 1953.350 p., 8 pls.
FonseCA, J.P. Migdolus morretesi Lane (Coleoptera, Anoplodermidae), uma broca eventual da cana-deaçúcar e do eucalipto. Arquivos do Instituto Biológico, São Paulo, v.25, p.29-40, 4 pls., 1958.

Gounelle, E. Note sur le genre Migdolus et description de la femelle du Migdolusfryanus West. (Col.). Bulletinde la Societe Entomologique de France, p.221-222, 1899.

Gravena, S. \& Busoli, A.C. Ocorrência de Migdolus sp. (Coleoptera: Cerambycidae) atacando feijoeiro (Phaseulus vulgaris L.) irrigado em Jaboticabal, São Paulo. Anais da Sociedade Entomológica do Brasil. v.14, n.1, p.165, 1985.

Guérin-Ménèville, F.E. Description de deux genres nouveaux de la famille des longicornes. Revue Zoologique, p.276-277, 1840.

Kasten Junior, P.; Arruda, F.C.O.; Vito, F.D. de;Oliveira, J.J. DE Controle de Migdolus spp. com inseticidas CR na usina São Manoel. Boletim Técnico Copersucar, n.46, p.33-36, 1989.

Kasten Junior, P.; Donzelli,J.L.;StriniJunior, A.E.;SAcomano, J.B.; VilhenA, E.O. Ocorrência de Migdolus spp. e insetos associados em solo de textura arenosa (Areias quartzosas). Boletim Técnico Copersucar, n.32, p.29-32, 1985.

Kasten Junior, P.; Terán, F.O.; Vito, F.D.; Manechini, C. Influência da época de plantio da cana-de-açúcar no controle de Migdolus sp. Boletim Técnico Copersucar, n.41, p.23-30, 1988.

LANE, F. Esboço monográfico dos anoplodermídeos. Revista do Museu Paulista, n.23, p.155-223, 1937.

Leal, W.S.; Bento, J.M.S.; Vilela, E.F.; Della Lucia, T.M.C. Female sex fheromone of the longhorn beetleMigdolus fryanus Westwood: N-(2‘S)-methylbutanoyl 2methylbutilamine. Experientia, n.50, p.853-856, 1994.

Machado, L.A.; Habib, M.; Leite, L.G.; Carregari, L.C.; Goulart, R.M.; Tavares, F.M. Patogenicidade de nematóides entomopatogênicos a ovos e larvas de Migdolus fryanus (Westwood, 1863) (Coleoptera: Vesperidae). Arquivos do Instituto Biológico, São Paulo, v.72, n.2, p.221-226, 2005. Disponível em: $\measuredangle$ http:// www.biologico.sp.gov.br/arquivos/V72_2/ machado.pdf>. Acesso em: 11 abr. 2006.

Machado, L. A.; НAbib, M.; Leite, L.G.; GollarT, R.M.; TAVARES, F.M.; C ALEGari , L.C.; L AinetI, D.O. Controle de Migdolus fryanus na cultura da cana-de-açúcar com 
nematóides.. In: REUNIÃO ITINERANTE DE FITOSSANIDADE DO INSTITUTO BIOLÓGICO RIFIB, 5., 2003, Catanduva, SP. Anais. Catanduva, 2003. p. 70-78.

Machado, L.A. Estudos biológicos e comportamentais de Migdolus fryanus (Westwood, 1863) (Coleoptera: Vesperidae) e sua interação com nematóides entomopatogenicos e outros agentes de mortalidades. 2006. 119f. Tese (Doutorado em Parasitologia) - Instituto de Biologia, Universidade Estadual de Campinas, Campinas, 2006.

NAKANO, O. \& ЈоKо, T. Considerações sobre a biologia e hábito do Migdolus morretesi Lane, 1937 (Coleoptera, Cerambycidae) REUNIÃO ANUALDASOCIEDADE BRASILEIRA DE ENTOMOLOGIA. 2., 1969, Recife, PE. Resumos.Recife, 1969. p.6.

NaKano, O.; Romano, F.C.B.; Pessini, M.M.O. Broca do rizoma (Migdolus spp.) In:Pragas desolo. Piracicaba, SP: ESALQ/USP, 2001. p.25-35.

Novaretti, W.R.T.; Nelli, E.J.; Carderán, J.O. Controle químico do Migdolus na cultura da cana-de-açúcar cana de ano e meio Boletim Técnico Copersucar, n.24, p.33-39, 1983.

Nunes, D.B. O estado da arte sobre Migdolus spp. (Coleoptera: Cerambycidae). In: O estado do conhecimento sobre Migdolus. 1996, p.5-10. [Workshop].

Pigatti, P. \& Pigatti A. Ensaios de campo para o controle do Migdolus morretesi Lane, em cana-de-açúcar. In: REUNIÃO ANUAL DA SOCIEDADE BRASILEIRA DE ENTOMOLOGIA, 1. 1968, Resumos., p.53-54 1968.

Pigatti, P.; Suplicy Filho, N. \& Pigatti, A. Ensaio para o controle de MigdolusmorretesiLane, praga da cana-deaçúcar. Biológico, São Paulo, v.23, p.217-219, 1966.

Pigatti, P.; Violante Neto, A.; \& Plgatti, A. Ensaios em laboratórios visando a seleção de inseticidas para o combate ao Migdolus morretesi Lane, praga da cana-de-açúcar. Biológico, São Paulo, v.28, p.201204, 1962.

Pizano, M.A. A guilera M.M.; V alente Neto, A.P.; Manechini, C. Avaliação da infestação natural deNeoplectanaglaseri Steiner, 1929 em Migdolus fryanus (Westwood, 1863) (Col.: Cerambycidae) In: CONGRESSO BRASILEIRO DE ENTOMOLOGIA, 7., Campinas, SP.Resumos.Campinas, 1987. p.165.
Pizano, M.A. Potencial de controle de Migdolus fryanus (Westwood, 1863) (Col.: Cerambycidae) através de armadilha de feromônio sexual. In: CONGRESSO BRASILEIRO. DE ENTOMOLOGIA. 8., 1991, Recife, PE. Resumos. Recife, 1991. p.331.

Pizano, M.A.; Aguillera,M.M.;M onteiro, A.R.; FerRAz, L.C.B. Incidence of NeoplectanaglaseriSteiner, 1929 (Nematoda: Steinernematidae) parasitizing Migdolus fryanus (Westwood, 1863) (Coleoptera: Cerambycidae). Entomology Newsletter, v.17, p.9-10, 1985.

Roccia, A.O. Estudos sobre a bio-ecologia e controle de Migdolus spp. (Col.: Cerambycidae) In:RelatórioAnual do setor de entomologia. Coopersucar, p.340-347, 1977.

Sansigolo, M.A.; Albuquerque, F.C. Fontanari, N.; Alonso, O. Descoberta da pupa deMigdolus fryanus Westwood (Col.: Cerambycidae). "Comunicação Científica". Brasil Açucareiro, v.98, n.5, p.10-11, 1981.

SvÁCHA, P.; WANG, J. \& CHEN, S. Larval morphology and biology of Philus antennatus and Heterophilus punctulatus, and systematic position of the Philinae (Coleoptera: Cerambycidae and Vesperidae).Annales de la Societé Entomologique de France (N.S.) v.33, n.3, p.323-369, 1997.

TerÁn, F.O.; Kasten JR., P.; De Vito, F.D.; Arruda, F.C.O. Experimentos de controle de Migdolus e pragas associadas, na Usina São Manoel.Boletim Técnico Copersucar, n. 42, p.38-43, 1988.

Teran, F.O.; Novaretti, W.R.T.; KastenJunior, P.Migdolus sp. einsetos associados.In:REUNIÃOTÉCNICA AGRONÔMICASOBREPRAGASDACULTURADACANA-DEAÇÚCAR. 1983. Piracicaba: Copersucar, 1983. p.25-31.

Teran, F.O.; Novaretti, W.R.T.; Kasten Junior, P.; Arrigoni, E.B.; Matos, C.A.O. Migdolusspp. e insetos associados. In: SEMINÁRIO DE TÉCNOLOGIA AGRONÔMICA CENTRODE TECNOLOGIA COPERSUCAR, 2., 1984, Piracicaba, SP. Anais, Piracicaba, 1984. p.313-326.

Wilcken, C.F.; Orlato, C.; Ortati A.L.T. Ocorrência de Migdolus fryanus (Coleoptera: Cerambycidae)emplantios de Pinus caribaea var. Hondurensis. RevistaÁrvore, v.29, n.1, p.171-173, 2005.

Recebido em 27/1/06

Aceito em 11/7/06 